\title{
STORYTELLING COMO UMA METODOLOGIA ATIVA NO ENSINO DE MATEMÁTICA
}

\author{
STORYTELLING AS AN ACTIVE METHODOLOGY IN TEACHING \\ MATHEMATICS
}

\author{
Elaine de Sousa Teodosio ${ }^{1}$
}

\begin{abstract}
RESUMO
No contexto atual de pandemia como forma de suprir a demanda pela efetividade do processo ensino e aprendizagem, em momentos remotos e híbridos, há uma busca constante por metodologias ativas, pois as metodologias tradicionais, que focam apenas na apropriação de técnicas ou conceitos puramente científicos, não são tão eficazes. Portanto este artigo tem como objetivo trazer uma atividade de Matemática, para alunos da educação básica, estruturada a partir da Metodologia Ativa Storytelling que consiste em uma narrativa que, no processo educacional, incorpora elementos pedagógicos que proporcionam aos estudantes, criatividade, senso crítico e interação. Os assuntos matemáticos contemplados, a partir das narrativas, são características do sistema de numeração posicional, resolução de problemas envolvendo números racionais e suas operações, as relações de proporcionalidade entre grandezas numéricas, resolução de problemas utilizando unidades de medida padronizadas e, também realizar conversões de unidades de medida. Além desses assuntos de Matemática, a atividade proporciona um debate sobre alguns temas transversais como Educação Financeira e a situação atual da pandemia, pois entendemos que o contexto econômico e sanitário exige que as aulas tragam essa discussão e, dessa forma, estaremos contribuindo para a formação dos alunos numa perspectiva crítica. Para isso, os estudos foram baseados em uma revisão sistemática de literatura em busca das contribuições das Metodologias Ativas. Destacamos que essa ferramenta oportuniza também um aprendizado baseado em experiências histórico-cultural no qual a partir de ações proativas professores e estudantes constrói e reconstrói valores e ideias baseado em uma problematização que favorece um ambiente colaborativo e significativo de aprendizagem.
\end{abstract}

Palavras-chave: Educação Matemática; Educação Financeira; Narrativa.

\begin{abstract}
In the current pandemic context as a way to meet the demand for the effectiveness of the teaching and learning process, in remote and hybrid moments, there is a constant search for active methodologies, since traditional methodologies, which focus only on the appropriation of purely scientific techniques or concepts, are not as effective. Therefore, this article aims to bring an activity of Mathematics, for students of basic education, with an Active Methodology that is Storytelling that consists of a narrative that, in the educational process, incorporates pedagogical elements that provide students with creativity, critical sense and interaction. The mathematical subjects contemplated, from the narratives, are characteristics of the positional numbering system,

\footnotetext{
${ }^{1}$ Mestra em Matemática em Rede Nacional pela Universidades Federal do Ceará (UFC). Técnica em Formação Docente na Secretaria de Educação do Ceará (Seduc/Crede 1), Maracanaú, Ceará, Brasil. Endereço para correspondência: Rua Osia Montenegro, 215, São Bento, Fortaleza, Ceará, Brasil, CEP: 60732-544. E-mail: elaine.teodosio@ prof.ce.gov.br.
}

ORCID iD: https://orcid.org/0000-0003-3778-7874. 
problem solving involving rational numbers and their operations, the proportionality relations between numerical quantities, problem solving using standardized units of measurement and also performing conversions of measurement units, in addition to these Mathematics subjects, the activity provides a debate on some transversal themes such as Financial Education and the current situation of the pandemic, as we understand that our economic and health context requires that our classes bring this discussion and, therefore, in this way we will be contributing to the training of our students in a critical perspective. For this, the studies were based on a systematic literature review in search of the contributions of Active Methodologies. We emphasize that this tool also provides learning based on historical-cultural experiences in which, based on proactive actions, teachers and students build and reconstruct values and ideas based on a problematization that favors a collaborative and meaningful learning environment.

Keywords: Mathematical Education; Financial education; Narrative. 


\section{Introdução}

O atual contexto da pandemia da Covid-19 fez com que nós professores buscássemos novas metodologias, em um curtíssimo prazo. É importante ressaltar, que além da necessidade, para fazermos o uso pedagógico das tecnologias digitais, é essencial formação, planejamento e investimento.

Diante desse contexto pandêmico muitos conhecimentos e habilidades foram tornando-se obsoletos e ultrapassados e, que resultou em uma busca para se apropriar de metodologias inovadoras cujas estratégias educacionais fossem centradas em estudantes ativos, através da resolução de problemas relevantes, integrando conceitos e utilizando recursos múltiplos e relevantes.

Baseadas nessas estratégias apresentaremos uma atividade de Matemática, estruturada com base numa Metodologia Ativa conhecida como Storytelling. Trata-se de uma narrativa que, no processo educacional, incorpora elementos pedagógicos que proporcionam aos estudantes, criatividade, senso crítico e interação.

Atualmente, no ensino de Matemática precisamos incorporar materiais e práticas que possibilitem a interação e a criatividade do aluno, portanto apresentaremos as contribuições do Storytelling como metodologia ativa e como uma ferramenta que pode contribuir para que o aluno entenda a matemática que está a sua volta.

\section{Metodologias ativas no ensino de matemática}

Concebemos a Educação Matemática a partir das dimensões política, social, histórica e cultural, cuja finalidade é a criação de indivíduos éticos e reflexivos que se posicionam criticamente em práticas matemáticas historicamente e culturalmente constituídas. (RADFORD, 2014).

Nessa perspectiva, as metodologias ativas de educação são válidas, tanto no ensino presencial quanto no ensino a distância, pois atende a essa demanda e o perfil dos alunos. Portanto, as aulas devem ser baseadas em estratégias de ensino que ofereçam desafios mais complexos, que desenvolvam, nos alunos, uma postura proativa, tanto nas tarefas individuais, quanto no trabalho colaborativo. Ressaltamos que isso é uma necessidade da sociedade atual. Neste contexto, é imprescindível uma mudança de postura do professor e do aluno e que as atividades sejam desenvolvidas em um trabalho conjunto entre ambos, e, portanto, a aula não estará baseada apenas na apropriação de 
técnicas ou conceitos puramente científicos. Logo, esse ambiente proporciona aos alunos uma formação cultural, no qual estes têm acesso a conhecimentos relativos às necessidades de criação dos conceitos estudados, o contexto cultural no qual surgiram, dentre muitas outras variáveis, influenciadas pela cultura e pelo meio social. Os PCN+ também reforçam quando afirmam que:

o pensar e o fazer se mobilizam e se desenvolvem quando o indivíduo está engajado ativamente no enfrentamento de desafios. Essa competência não se desenvolve quando propomos apenas exercícios de aplicação dos conceitos e técnicas matemáticas, pois, neste caso, o que está em ação é uma simples transposição analógica: o aluno busca na memória um exercício semelhante e desenvolve passos análogos aos daquela situação, o que não garante que seja capaz de utilizar seus conhecimentos em situações diferentes ou mais complexas (BRASIL, 2006, p.112).

Nesse sentido a BNCC também nos assegura isso quando propõe a superação da fragmentação radicalmente disciplinar do conhecimento, o estímulo à sua aplicação na vida cotidiana, a importância do contexto para dar sentido ao que se aprende e o protagonismo do estudante em sua aprendizagem (BRASIL, 2018)

Dessa forma, pactuamos com Radford (2014) ao defender que o ensino e a aprendizagem também produzem subjetividades. Como consequência, devemos fazer um esforço para entender as produções de saberes e subjetividades na aula e promover ações didáticas e pedagógicas que fomentam um ensino e uma aprendizagem significativos, ou seja não alienante.

\footnotetext{
El término ‘Aprendizaje y enseñanza significativos' hace referencia a aquellas formas pedagógicas de acción que conllevan: (1) a una comprensión profunda de los conceptos matemáticos y (2) a la creación de un espacio político y social dentro del cual puedan desarrollarse subjetividades reflexivas, solidarias y responsables. La comprensión y la producción de saberes y subjetividades en el aula, así como la identificación de formas pedagógicas de acción que conlleven a una enseñanza y aprendizaje significativos son dos de los objetivos de la teoría de la objetivación(RADFORD, 2014, p.136) .
}

De acordo com Radford (2014) ensino e aprendizagem significativos são ações pedagógicas que levam a uma compreensão profunda dos conceitos matemáticos e, também promovem um espaço político e social, no qual possam desenvolver subjetividades reflexivas, solidárias e responsáveis. 
Para Radford (2014), a Matemática é um meio e não o fim, ou seja, é um instrumento para aprender a ser em matemática e, não simplesmente aprender a fazer matemática no sentido de resolver problemas.

Nessa perspectiva apresentaremos uma das propostas inovadoras de Metodologias Ativa, que nas últimas décadas surgiram diferentes modalidades e instrumentos como storytelling (narrativas), jogos aplicados à educação, sala de aula invertida, apresentações de painéis/exercícios pelos alunos, construção de experimentos em sala de aula; Peer Instruction $^{2}$ (aprendizagem aos pares), Ensino Híbrido ${ }^{3}$, utilização de Quiz/Test Questions $^{4}$. Estes são apenas alguns exemplos, vale ressaltar que alguns ainda são carentes de discussões mais consistentes nos meios acadêmicos e outros já estão consolidadas em nichos específicos de pesquisas.

É importante salientar que propostas de ensino com uma abordagem pautadas em metodologias ativas têm como princípios: autonomia, reflexão, problematização da realidade, trabalho em equipe, inovação, professor como mediador, facilitador, ativador e o aluno no centro do ensino e da aprendizagem (DIESE; BLASEZ; MARTINS, 2017). Além disso,

as metodologias ativas têm o potencial de despertar a curiosidade, à medida que os alunos se inserem na teorização e trazem elementos novos, ainda não considerados nas aulas ou na própria perspectiva do professor. Quando acatadas e analisadas as contribuições dos alunos, valorizando-as, são estimulados os sentimentos de engajamento, percepção de competência e de pertencimento, além da persistência nos estudos. Entre outra. (BERBEL, 2011, p.28).

Dito isso, apresentaremos uma proposta de atividade baseada no Storytelling, ainda carente de discussão principalmente na Educação Matemática, uma modalidade que

\footnotetext{
${ }^{2} \mathrm{O}$ método Instrução entre Pares ou, no original, Peer Instruction, criado pelo físico Eric Mazur, professor da Universidade de Harvard, explora a interação entre os alunos durante as aulas expositivas e foca os conceitos fundamentais, tornando o conteúdo significativamente mais acessível.

${ }^{3}$ Ensino hibrido é uma metodologia que tem como objetivo aliar métodos de aprendizado online e presencial para captar o que existe de bom em cada ambiente para potencializar a experiência educativa, destacamos que é preciso aplicar algumas técnicas e manter os alunos sempre sob a supervisão de um profissionalas Notas de Rodapé, elas devem ser alinhadas a esquerda, com fonte tamanho 10 e espaçamento simples. Não há restrição quanto ao uso de Notas de Rodapé, mas espera-se o bomsenso do(s) autor(res).

${ }^{4}$ Sobre Quiz/Test Questions são plataformas para avaliação de conhecimentos sobre determinado assunto. Toda a lógica desse método passa por um questionário com alternativas onde o avaliado julga a opção mais correta. Essas ferramentas geralmente são acessadas por dispositivos eletrônicos, para facilitar a propagação e controle de respostas das questões.
} 
atende aos princípios da metodologia ativa, além de proporcionar uma experiência de aprendizagem que tem como objetivo inserir o aluno em um contexto de experimentação que proporciona ao mesmo um protagonismo no seu aprendizado.

\section{Uma atividade de Matemática baseada no Storytelling}

Segundo Diese; Blasez; Martins (2017), a estratégia de ensino será baseada no storytelling,

1) contribui de forma significativa para o desenvolvimento da autonomia do estudante à medida que favorece o sentimento de pertença e de coparticipação, tendo em vista que a teorização deixa de ser o ponto de partida e passa a ser o ponto de chegada;

2) problematiza e reflete sobre a realidade, pois o estudante tem um papel ativo como protagonista do seu processo de aprendizagem, interagindo com o conteúdo ouvindo, falando, perguntando e discutindo;

3) estimula o trabalho em equipe, pois há movimento de interação constante com os colegas e com o professor;

4) exige inovação, como sinônimo de inventar e criar, tanto da parte do professor quanto do aluno.

5) possibilita o professor assumir uma postura investigativa de sua própria prática, refletindo sobre ela a fim de reconhecendo problemas e propondo soluções;

6) ativa o aprendizado dos estudantes, colocando-os no centro do processo.

Além disso, destacamos que toda ação pedagógica deve estar baseada em um planejamento pedagógico, com seus objetivos de aprendizagem bem definido. Diante disso, o planejamento para o uso do storytelling nas aulas de Matemática envolvem quatro etapas que são: a definição dos objetivos educacionais, gerais e específicos; o planejamento e execução das atividades a serem desenvolvidas ao longo do processo de aprendizagem; a análise, processamento e avaliação da experiência pelo aluno, que deve ser específico para cada atividade; e a avaliação final, fundamental para a consolidação do processo de aprendizagem esperado (VALENÇA; TOSTES, 2019).

O storytelling, instrumento usado na atividade didática, consiste numa narrativa dentro de um contexto social, associada a uma experimentação, baseadas em ações atrativas, podendo proporcionar reflexões e críticas. Por ser uma ferramenta pedagógica o professor deve estruturar a narrativa, planejando de forma que seus objetivos 
estabelecidos sejam alcançados. Portanto o seu uso é moldado a partir da escolha do tema, processos e dinâmicas, com o objetivo de promover atividades de incentivo e "provocar o incômodo" necessário para que o engajamento dos estudantes ocorra de forma orientada, mas não totalmente controlada (VALENÇA; TOSTES, 2019).

A atividade matemática no supermercado baseada no storytellling consiste na elaboração de uma narrativa pelos alunos a partir das imagens dadas pelo professor. As imagens foram organizadas no Canva, um aplicativo de designs que cria materiais criativos e de impactos (Figura 1). Baseado nas imagens espera-se que os alunos façam referências a assuntos de matemática como transformação de unidades, operações, além de educação financeira, pois espera que eles relatem a compra do leite com o menor custo benefício. Nessa atividade também pode ser trabalhada a situação atual da pandemia, pois as pessoas estão usando máscara

Figura 1 - Capa da atividade

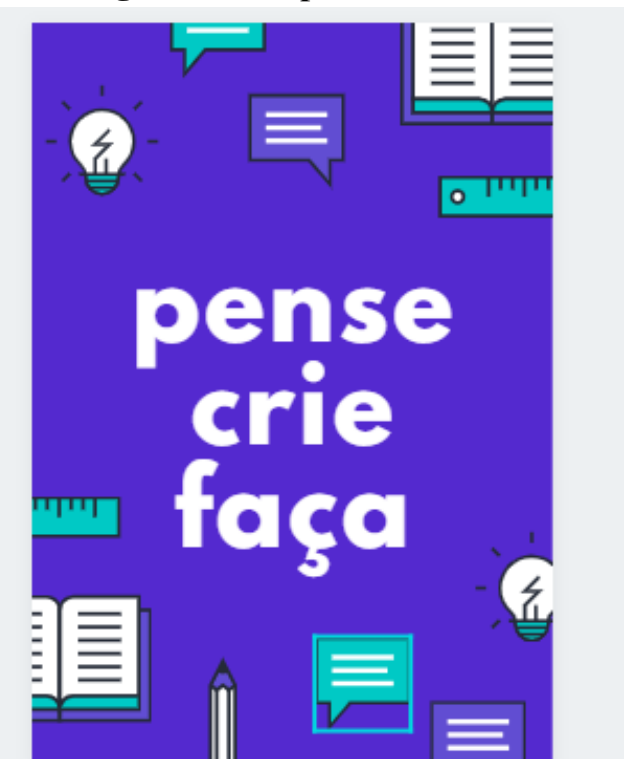

Fonte: Canva

É importante deixar a imaginação dos alunos fluir, trabalhar a criatividade e a escrita, para no momento posterior juntar as informações, trazidas por eles, a partir das imagens e dados como o rapaz que deseja comprar $4 \mathrm{~kg}$ de leite, o supermercado oferece o leite em três embalagens $200 \mathrm{~g}, 800 \mathrm{~g}$ e $1 \mathrm{~kg}$ e o preço de cada um (Figura 2) e, assim explorar os objetivos traçados. Assim, a partir das narrativas dos alunos, os professores podem explorar características do sistema de numeração posicional, resolver problemas 
envolvendo números racionais e suas operações, as relações de proporcionalidade entre grandezas numéricas, resolver problemas utilizando unidades de medida padronizadas, também realizar conversões de unidades de medida.

Figura 2 - Supermercado

\section{MATEMÁTI C A}

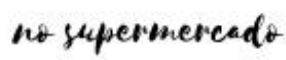

ELAINE TEODOSIO

\section{Observe as imagens e crie um texto}

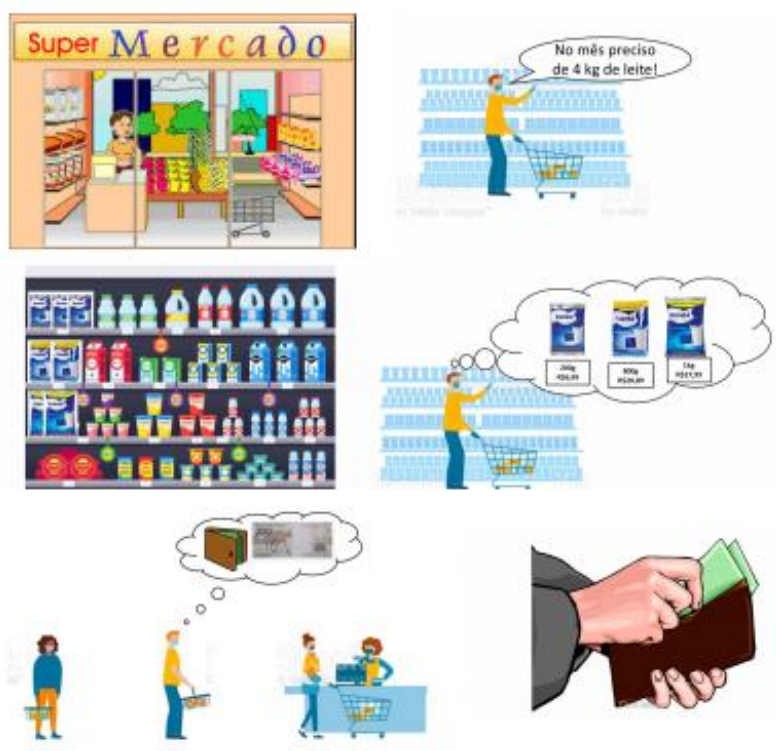

Fonte: próprio autor (2020)

Essa atividade permite, além dos conteúdos matemáticos, já citados, trabalharmos temas transversais atuais e de impacto social como a prevenção ao coronavírus e outro não menos importante, diante do contexto econômico, que é a Educação Financeira. Entendemos que trazer essa discussão para as aulas estaremos contribuindo para a formação dos alunos numa perspectiva crítica, compactuando, assim com Araújo (2009, p.145), quem afirma que: "educar o consumidor é educar o cidadão, e a escola tem a função histórica e social nesta direção". Destacamos, ainda que a BNCC inclui a Educação Financeira como um tema transversal que deve estar presente nas escolas, pois 


\begin{abstract}
A Educação Financeira é fundamental para que o cidadão aprenda a importância das finanças no seu cotidiano e possa usar racionalmente seus recursos para obter qualidade de vida. As crianças, futuras consumidoras, precisam desde cedo serem preparadas para lidar bem com o dinheiro. Nesse sentido, a família e a escola são importantes aliadas na construção de novos padrões comportamentais e na formação das novas gerações. Por meio da Educação Financeira é possível formar cidadãos conscientes e mais preparados para participar do desenvolvimento econômico e social do país (COUTINHO E TEIXEIRA, 2013, p.3-4).
\end{abstract}

A Educação Financeira é um tema de caráter interdisciplinar, na maioria das vezes, essa temática está ligada às aulas de Matemática, porém é um tema que merece ser discutidos em vários âmbitos como histórico, social e cultural, não se limitando apenas a tópicos como sistema monetário e juros, por exemplo, esse assunto exige um cenário com uma estratégia de ensino de caráter crítico, pois

\begin{abstract}
Percebemos assim, que a sociedade demanda uma necessidade de formação de cidadãos que estejam preparados para administrar suas finanças de maneira consciente e crítica. Essa formação tem como principal contribuição as ações educacionais, ou seja, a escola tem um importante papel no desenvolvimento crítico dos sujeitos. A Educação Financeira precisa ganhar espaço, não apenas como uma temática interdisciplinar, mas como uma importante ferramenta de desenvolvimento que possibilite a emancipação dos sujeitos através de um ensino pautado na perspectiva da criticidade, e considerando que essa temática ganha destaque nas aulas de Matemática, cabe aos docentes estimularem seus estudantes com atividades e aulas. (SILVA, 2016, p.9)
\end{abstract}

A proposta didática usando o storytelling é uma ferramenta de múltiplas potencialidades, pois a partir das narrativas dos alunos os professores podem explorar os assuntos de Matemática, os temas transversais e ainda pode ocorrer de os alunos trazerem informações diferentes dessas propostas e, com isso, aumenta também o leque de objetivos a serem alcançados com a atividade. Dessa forma, corroboramos o pensamento de D’Ambrosio (2012), ao defender que o acesso a um maior número de instrumentos e técnicas intelectuais dá, quando devidamente contextualizado, muito maior capacidade de enfrentar situações e de resolver problemas novos, de modelar adequadamente, uma situação real para, com esses instrumentos, chegar a uma possível solução ou curso de ação.

Ressaltamos que o planejamento e o empenho do professor são muito importantes para o engajamento dos alunos no storytelling e que essa experiência tem a função de provocar emoções, questionamentos, novas ideias e imaginações, promovendo, com isso, 
uma aprendizagem por excelência que é a capacidade de explicar, aprender e compreender, de enfrentar criticamente situações novas (D’ AMBRÓSIO, 2012).

\section{Considerações finais}

Entendemos que a atividade proposta, o storytelling, é uma estratégia de ensino inserida nas metodologias ativas, no qual o estudante constrói a narrativa e a partir dela o professor sistematiza o conhecimento, portanto há uma interação maior do aluno na construção do seu próprio conhecimento, o mesmo passa até um controle maior do seu aprendizado, pois a dinâmica proposta exige ações e construções mentais como: leitura, escrita, comparação, observação, imaginação, criatividade, interpretação, análise e tomada de decisões. Essa ferramenta oportuniza também um aprendizado baseado em experiências histórico-cultural, pois a partir da narrativa, em uma atitude proativa, professores e estudantes constroem e reconstroem valores e ideias e assim a problematização favorece um ambiente colaborativo de aprendizagem

Ressaltamos a importância do planejamento da aula e das estratégias de ensino, pois a escolha de uma teoria e/ou uma metodologia, por si só não é eficaz para atingir os objetivos de aprendizagem. Além disso, para alcançar os objetivos almejados é importante que os professores compreendam a metodologia.

Portanto compreendemos que a proposta de atividade (re)significa o ambiente escolar ao promover interações entre os sujeitos e o conhecimento, o protagonismo e o desenvolvimento da autonomia pois é um ambiente rico que aguça a curiosidade, o questionamento e o debate, possibilitando também os alunos trazerem para aula elementos novos, que não estavam previstos pelo professor. É importante que esses elementos não previstos sejam analisadas e acatadas, pois, assim, o professor favorecerá o pertencimento do aluno no processo de aprendizagem.

\section{Referências}

ARAÚJO, Regina Magna Bonifácio de. Alfabetização econômica: compromisso social na educação das crianças. São Bernardo do Campo: Universidade Metodista de São Paulo, 2009

BRASIL. Orientações Educacionais Complementares aos Parâmetros Curriculares Nacionais (PCN+). Ciências da Natureza e Matemática e suas tecnologias. Brasília: MEC, 2006 
BRASIL. Base Nacional Comum Curricular (BNCC). Brasília: MEC, 2018

BERBEL, N.A.N. As metodologias ativas e a promoção da autonomia de estudantes. Semina: Ciências Sociais e Humanas, Londrina, v. 32, n. 1, p. 25-40, janjun. 2011.

COUTINHO, C. Q. S.; TEIXEIRA, J. A educação matemática e o seu papel na construção da educação financeira. In.: VII CIBEM, Montevideo, Uruguay, 2013.

D'AMBROSIO, Ubiratan. Educação Matemática: da teoria à prática. Campinas: Papirus, 2012.

DIESEL, A., BALDEZ, A.L.S., MARTINS, S.N. Os princípios das metodologias ativas de ensino: uma abordagem teórica. Revista Thema, v.14, n.1. p. 268-288, 2017.

M. Valença, M., \& Balthazar Tostes, A. P. (2019). O Storytelling como ferramenta de aprendizado ativo. Carta Internacional, v. 14, n. 2, p. 221-243, 2019.

https://doi.org/10.21530/ci.v14n2.2019.917

RADFORD, L. De la teoría de la objetivación. Revista Latinoamericana de Etnomatemática. Vol. 7, No. 2, junio-septiembre de 2014

SILVA, Arlam Dielcio Pontes. Educação Financeira em Aulas de Matemática: ambientes de aprendizagem a partir de atividades propostas em livros didáticos. In: ENCONTRO BRASILEIRO DE ESTUDANTES DE PÓS-GRADUAÇÃO EM EDUCAÇÃO MATEMÁTICA, 23., 2016. Curitiba, PR

Recebido em: 07 / 03 / 2021

Aprovado em: 17 / 04 / 2021 